\title{
Kennedy Town swimming pool, Hong Kong, China - an NEC journey
}

1 Kam Woon Mak BSC, MSc, MEng, PE, SE, MASCE, NECReg Director, Infrastructure, China Region, WSP, Hong Kong, PR China (corresponding author: Kam-Woon.Mak@wsp.com)

2 Stephen Hamill BSC, CEng, MICE, NECReg Project Manager - Technical Support, MTR Corporation, Hong Kong, PR China
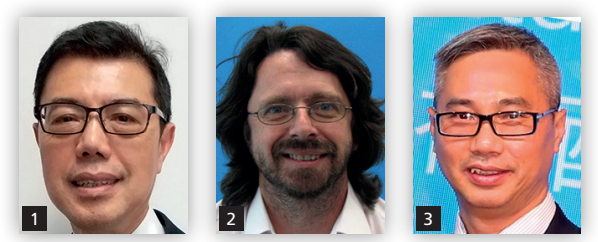

The stylish new Kennedy Town community swimming pool in Hong Kong was designed and built in two similar phases between 2008 and 2017. It replaced an original pool on the site, which had to be demolished during construction of the new West Island line. Client MTR trialled the NEC3 Engineering and Construction Contract for the $\mathrm{f} 64$ million second phase of the pool to see how it compared with the conventionally procured first phase. This paper describes the tendering, team-building and construction performance of the second phase and shares the lessons learned on NEC contract administration and implementation.

\section{Introduction}

Kennedy Town swimming pool was a reprovisioning project designed and constructed by MTR Corporation Limited (MTR) for the Leisure and Cultural Services Department of the Government of Hong Kong Special Administrative Region. Opened in February 2017, it replaces an existing community swimming pool on the site that had to be demolished to make room for construction of Kennedy Town station of the new West Island railway line. Figure 1 shows the new pool after completion.

The pool project was constructed in two phases to suit the West Island line works. The initial plot of land was made available in June 2009 and phase 1 - consisting of a $50 \mathrm{~m}$ open-air pool and smaller leisure pool - was completed and opened to the public in May 2011. However, phase 2 was on a railway tunnelling shaft site and the land was not available until September 2014.

In 2014, MTR decided to trial the NEC3 Engineering and Construction Contract (ECC) (NEC, 2013) and selected phase 2 of the pool reprovisioning project for the trial. The works comprised the following facilities

\footnotetext{
- $15 \mathrm{~m} \times 50 \mathrm{~m}$ indoor multi-purpose pool

- $12.5 \mathrm{~m} \times 25 \mathrm{~m}$ indoor training pool

- two indoor spa pools

- family/disabled changing rooms

- lifeguard staff room and control room

- first-aid room

- building services plant rooms

- three independent filtration plant rooms

- public open space.
}

Figures 2 and 3 show the pools and open space, respectively.
Client MTR appointed Farrells as the architect for both phases of the pool design. The design of engineering works was sublet to WSP Parsons Brinckerhoff (WSP PB), which undertook the role as lead engineering designer civil, structural and building services designs.

The NEC ECC form selected for phase 2 was Option A (priced contract with activity schedule) with two amendments covering specific client requirements. These were to

- maintain certifying processes and procedures with respect to time requirement for project manager's certification upon completion, as well as codes of conduct for compliance by the contractor, subcontractor and their employees

- include specific requirements with respect to parent company guarantees and performance bonds.

In addition, NEC clauses on weather conditions were not considered appropriate for Hong Kong, so these were amended to suit local weather conditions. Furthermore, contract data part one was amended to cover re-measurement of piling work as a fair system to pay the contractor based on actual work done on site. Re-measurement of piling work is also a common practice adopted by the client.

Phase 1 contractor Paul Y. Construction Company, Limited was selected as the phase 2 contractor in 2014 following the normal competitive tendering process adopted by the client. It was the contractor's first NEC construction contract as main contractor.

Adjudication is the default dispute-resolution method under the NEC contracts. John Battersby of BK Asia Pacific was the named adjudicator for the contract. BK Asia Pacific was also employed as NEC advisor, conducting and facilitating a number of NEC workshops during the course of the project, including workshops relating to disputed issues. 


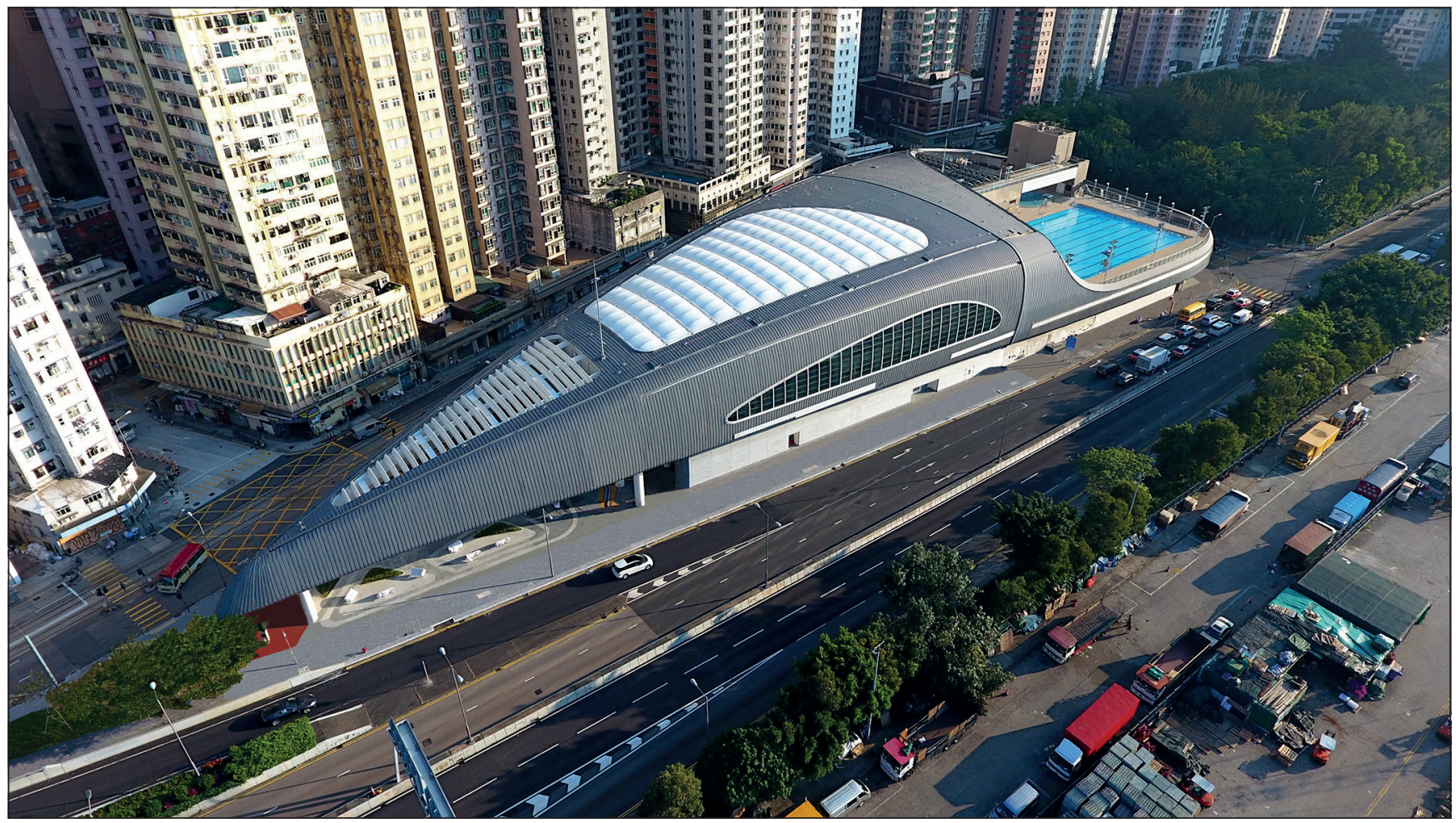

Figure 1. External view of completed indoor-outdoor pool complex

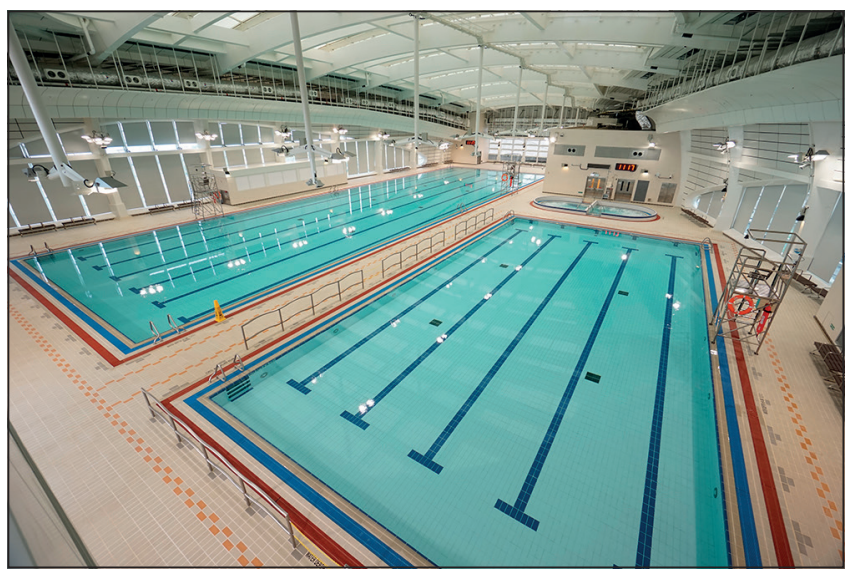

Figure 2. Phase 2 indoor pools

The HK\$671 million ( $£ 64$ million) phase 2 contract duration was 26 months. Completion was achieved in October 2016, $2 \cdot 5$ weeks ahead of schedule.

\section{Preparation for tender issue and submission}

Since contract documentation under NEC was very different from that used under the client's conventional lump-sum contract for phase 1, client staff spent over 6 months working with the NEC advisor to generate a whole new suite of contract documentation

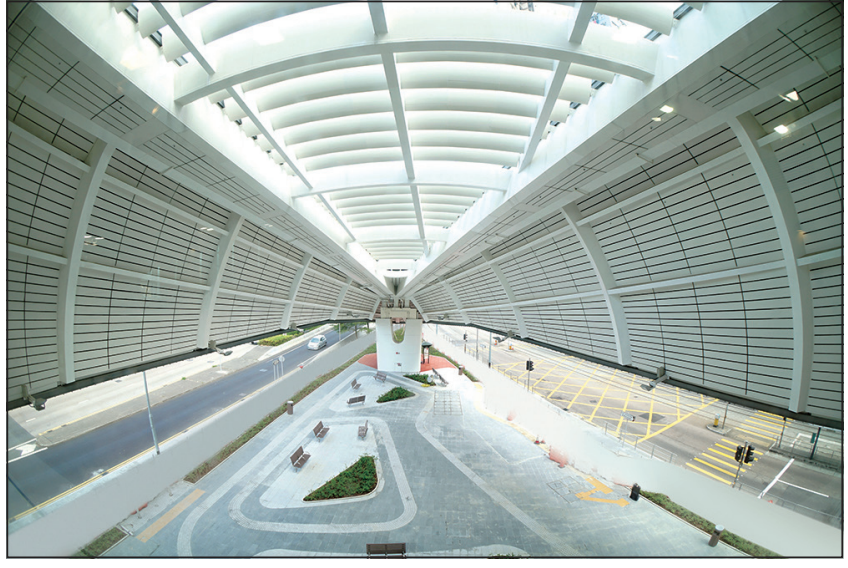

Figure 3. Phase 2 public open space

prior to tender issue. Client staff together with the consultant's staff also attended a number of workshops to receive training on NEC documentation.

The final documentation included

- letter of acceptance

- letter of clarification

- contract (NEC3 ECC Option A)

- form of tender - fixed price, contract data part one and part two

- works information

- formal agreement. 
A presentation of phase 2 contract documents with emphasis on NEC aspects was made to relevant Hong Kong government departments, including the user and maintenance departments, to facilitate their understanding of NEC clauses. This was to ensure that government requirements during the handover stage could be clearly stipulated in the contract without any ambiguities, and to avoid changes as much as possible.

Being based on the NEC3 ECC, the phase 2 contract was written to encourage a more collaborative approach by both the contractor and client. By agreeing payment schedules through collaboration and discussion between both parties, rather than simply imposing one upon the contractor at tender award, the contractor effectively took responsibility to deliver the works on the key dates that it set. Much of the tension and distrust that can arise against artificially imposed payment dates driven by the client alone was therefore removed. In addition, the works information documents were more contract-specific in nature.

The contract set strict criteria with respect to

- responsibility of all parties to raise and resolve design and construction issues as soon as they become aware of them

- time frames for resolving issues, with clear default positions if either party did not comply with these clearly set out time frames

- responsibility for keeping programmes and cost updated throughout the contract period in real time against the issuing of instructions

- clear guidelines and timelines for dispute resolution that ensured disputes were raised and closed out within the contract period and not 'kicked down the road' to the end of the contract.

In essence, the partnering principles and good working practices that have been promoted by the client for many years are effectively bound into the NEC form of contract, making them mandatory rather than voluntary.

Given the project was the first NEC contract for both the client and contractor, and had a tight completion schedule, the contractor developed its project organisation specifically for the NEC workflow structure. The contractor was fully aware of the significance of assigning proficient and sufficient planning engineers to work on the technical proposal at an early stage to respond to the client's invitation to bid.

The contactor's planning team members were therefore well trained and very familiar with the site constraints, logistic arrangements and operational requirements. Their major tasks included site planning, construction programme and progress reporting, and programming analysis of the compensation events.

During the tender stage, the contractor clearly understood the NEC contractual requirements to provide a fast response to additional work and/or revised work instructions issued by the project manager to achieve agreement on the time and cost impacts before works commenced. As such, the contractor ensured that its commercial team had

a proactive quantity surveying team for timely valuation of all commercial items

- team members that were readily available at the time of contract award
- a well-built structure with two managers and four project surveyors

- staff familiar with complex and fast-track project management.

\section{Team building}

In the early stages of phase 2, there was still a legacy 'them and us' attitude to project management on both sides from having worked together previously on conventional forms of contracts. In addition, the designers were reluctant to accept design issues raised by the contractor due to concerns of potential liability issues and cost implications. Paperwork, especially early warnings, started to accumulate.

Although weekly meetings were held to update the relevant registers - including the early warning register, the compensation event register and the programme register - meetings were not productive. Attendees representing the designers, contractor and client failed to understand the collaborative approach needed to manage an NEC contract and defended their own interests to protect their contractual positions. This was observed by project team leaders, who had the advantage of going through several NEC training sessions during tendering and were aware of the need for a fundamental change in mindset down through all levels of the team.

Workshops were immediately arranged to educate all staff on the NEC behavioural needs and to build up trust. The leaders of the project team also worked together collaboratively to set an example for the team members to follow. The contractor's staff were actively encouraged to report design deficiency issues and the design team were praised for early resolution rather than criticised for the original errors.

Solutions to design and construction issues were discussed openly at team meetings attended by the client, designers and contractor. The solutions were discussed jointly through working meetings right there and then, rather than being taken away for review, amendment, rejection, amendment, submission, further disagreement, agreement and so on - which is the normal 'silo' approach adopted in conventional contract forms.

As the team became more used to the collaborative working approach, they got to know each other better. Many issues that would normally have been formally submitted, causing delay and friction in a normal contractual environment, were resolved 'off-line' in one-on-one discussions and never even made it into the early warning system. The teams shared the same office and socialised together. Partnering events were genuine celebrations which both teams looked forward to and enjoyed. They were held regularly and always well attended from senior management level right down to the site security guards.

A bond became evident across team members, who would try their best to help both each other and the project with a greater understanding of each side's needs. This was exemplified by the contractor's efforts to help the client with challenging corporate relationship issues involving the district council's late design requirements. The contractor completed limited additional work at its own cost, while the client went the extra mile to assist the contractor in achieving essential government approvals whenever they ran into bureaucratic obstacles. 


\section{Resolving problems}

The following were two significant events experienced by the project team as lessons learnt in the phase 2 contract. These two events, if not resolved through collaboration of all members of the project team, would have caused significant time and cost impact to the project.

Shortly after construction started, a significant design issue was raised by the contractor regarding the correct level of eight pile caps and their connecting tie-beams by way of early warnings. Based on normal practice, if a design issue is raised by the contractor, the designer would simply work out the correct design data and issue the contractor with a revision, without involving the contractor or client.

After assessment by the designer, it was concluded that the pile caps in question had to be lowered by an average of $800 \mathrm{~mm}$, which would have had a great impact on the cost and programme. Since both the client and contractor agreed that the designer needed to understand the site constraints on excavation, the client, contractor and designer jointly held many meetings and site visits to make sure the solution put forward by the designer would be of least cost and least time impact to the project.

The client, contractor and designer worked together to revise the design related to the affected pile caps and their connecting tiebeams. A quotation on additional quantities, manpower and time requirements was then submitted by the contractor and assessed by the client based on the least-cost and least-time-impact principle. This significantly reduced the impact to the project to achieve a win-win situation on such a challenging issue.

The second significant event affected the building services contractor, which had come into the project late and had a team leader with very limited training and knowledge of how NEC contracts differ from conventional contracts. The 'openness and trust across all parties' approach of the main contractor was not so evident in the building services contractor's approach to its works. The team leader was more familiar with the traditional adversarial approach, whereby he would rely on being able to generate delay claims in the event of problems rather than jointly seeking solutions with the team.

The issue was not picked up in time by the senior management of both the contractor and the client. Delays in building services progress were not being accurately reported and, with about 2 months to completion, there was a marked increase in early warning notices from the building services team on issues which should have been flagged up much sooner. Crucial handover dates started to be missed, and a blame culture emanating from the building services section was detected.

Fortunately, the strength of the relationship built up across all other parts of the team held firm. It was recognised that the building services team was in trouble and all other parties rallied around them to help out. There was no blame attributed for the delays, just a concerted effort to help get the project over the line. The outcome was that the 4 weeks that the project had been ahead of the programme slipped, but only to $2 \cdot 5$ weeks, which helped preserve the contractor's bonus for early completion under ECC secondary option X6.

Had the team fallen into the conventional practices of blame and taken a contractual path to addressing the many early warnings being raised, it would most certainly have lost the whole 4 weeks advantage and perhaps more.

\section{Measurable performance}

A selection of key performance indicators (KPIs) and related tools to measure documentation and design change management, cost control and programme management for the phase 2 contract were adopted by the project team (Figures 4 and 5). The figures illustrate that while the NEC contract did not eradicate the need for design changes, it did greatly improve the early detection and resolution rate of design errors, allowing them to be addressed with reduced impact on both cost and programme.

Of particular note is Figure 5 illustrating the detection of design issues using the early warning system. The NEC culture of collaboration and advance problem-solving pushed the discovery of potential issues much earlier in the contract period (that is to the left of the bar chart), allowing earlier resolutions and review of potential knock-on impacts.

Also of great significance are the turnaround periods achieved against submissions made by the contractor. These included 323 early warnings submissions and 125 compensation events, the latter being completed in an average of $10 \mathrm{~d}$. By adhering to the requirements within NEC for real-time review and resolution of issues within predetermined time frames, turnaround periods were kept to a minimum, which helped to control cost and programme overruns.

\section{Summary and conclusions}

A significant factor identified during phase 2 was the development during the course of the project of a strong teamwork ethos among the site representatives from the client and contractor. This, it is considered by the project team, had a major influence on the project outcome. It demonstrated that projects using NEC can effectively engender a oneteam mentality with tangible benefits in terms of improving administration efficiency, reducing disputes and improving project outcomes.

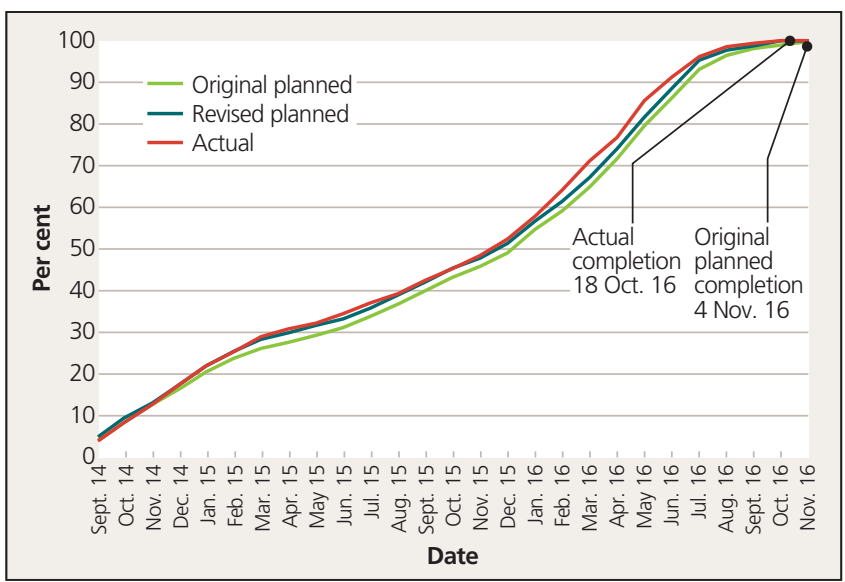

Figure 4. Graph showing the actual progress against the planned and revised planned progresses of the project 


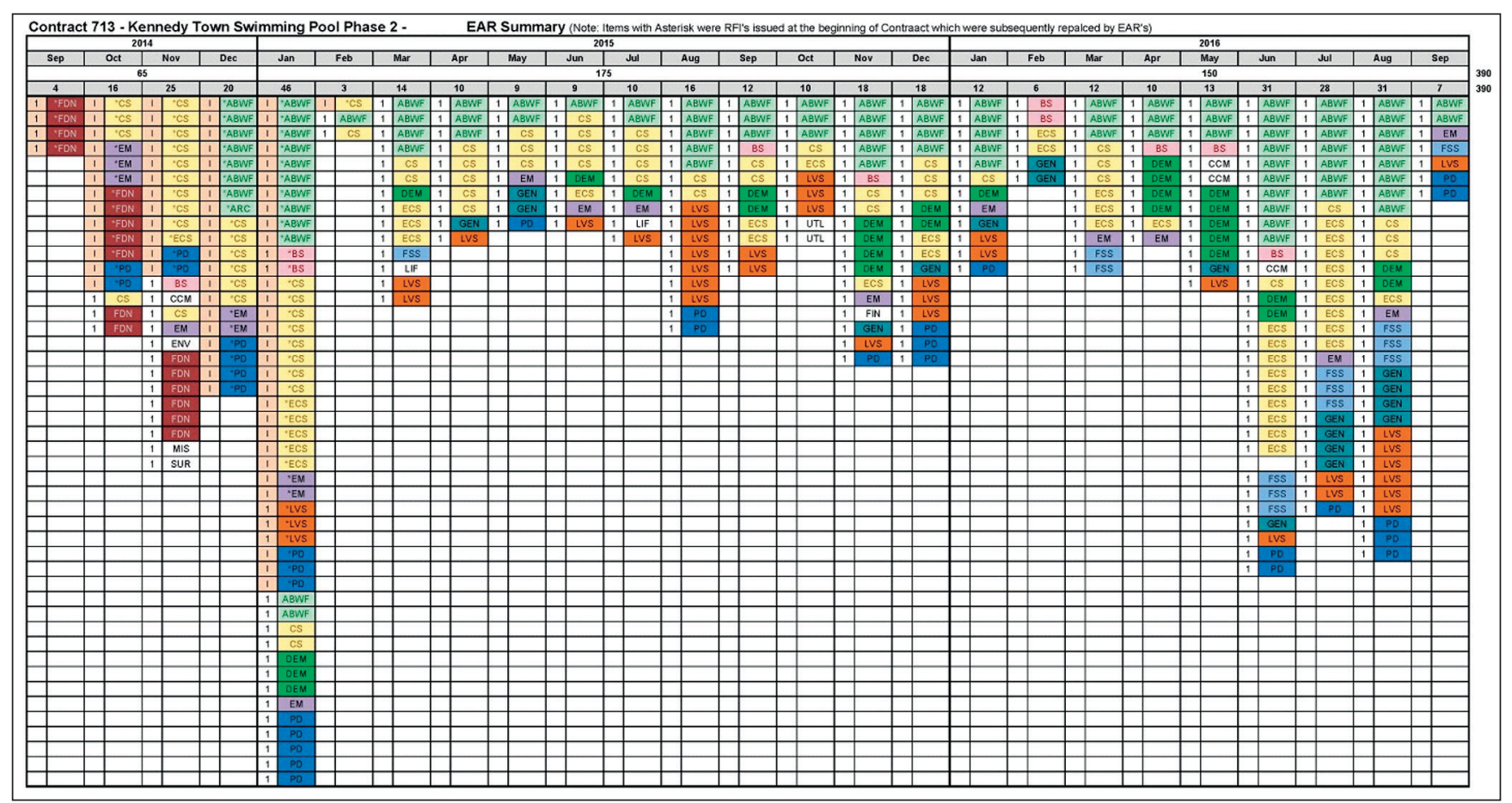

Figure 5. Early warning submission rate in respect of various architectural and engineering disciplines

The one-team philosophy was achieved not only by conducting the usual partnering-style joint team-building and social activities but also by adhering to the following

- fully implementing and utilising NEC contract procedures, which require the parties to deal with the time and cost issues contemporaneously

- strictly following time regimes set out in NEC for designated actions by both parties

- carrying out clear and unambiguous contract drafting in advance of contract award

- following closely the NEC risk management regime, which necessitates proactive and innovative risk management

- ensuring alignment of objectives by way of financial incentives

- enlisting senior management engagement and support for the project from both the client and contractor

- demonstrating a willingness on the part of the project team to go the extra mile to make the project a success

- instilling a willingness for both sides to compromise to avoid disputes.

However, since collaborative NEC contracts are still not the norm in Hong Kong, NEC projects do require a mindset change and in-depth understanding from project participants using the contract for the first time. This must include all key players in the project team - project manager, contractor, subcontractors, suppliers and consultants.

At the outset of projects using NEC, it is important that the project team's ethos and understanding of expectations are developed as quickly as possible. Even with the team for this project, there was a learning curve and a slow start before the project team fully embraced NEC collaborative philosophy.
The timely completion of the project, and the enhanced project team working relationship, was also significantly impacted by the agreement of a plan for early completion and an associated bonus for early completion under ECC secondary option X6. This saved resources costs on both sides, earned the contractor an enhanced profit, and encouraged the project team to work closely and collaboratively together to achieve a clearly designated common objective.

It is apparent that the processes and procedures set out in NEC individually are not revolutionary. However, when applied collectively and with a common philosophy, the provisions help to ensure that each of the various project administration touch-points are dealt with timeously, prescriptively, fairly and efficiently. This leads to an increased confidence and trust among the project team that counterparts and fellow team members will administer the project in ways which are predictable, and in accordance with good practice and the contract provisions.

For future projects in Hong Kong the NEC contract suite, if properly implemented and with the full support of participants, could help to bring about improvements in achieving planned completion dates with better cost control. The Hong Kong government is pushing for increased usage of NEC on its projects and has recently published practice notes and standard amendments for general use on all its NEC projects.

The construction industry in Hong Kong is, as a consequence, likely to become steadily more familiar with the changes in project management and collaborative practices necessary to implement an NEC contract successfully. Future performance of Hong Kong NEC projects, where the parties are already aware of the benefits and requirements of collaboration, should therefore show even more of a performance improvement. 


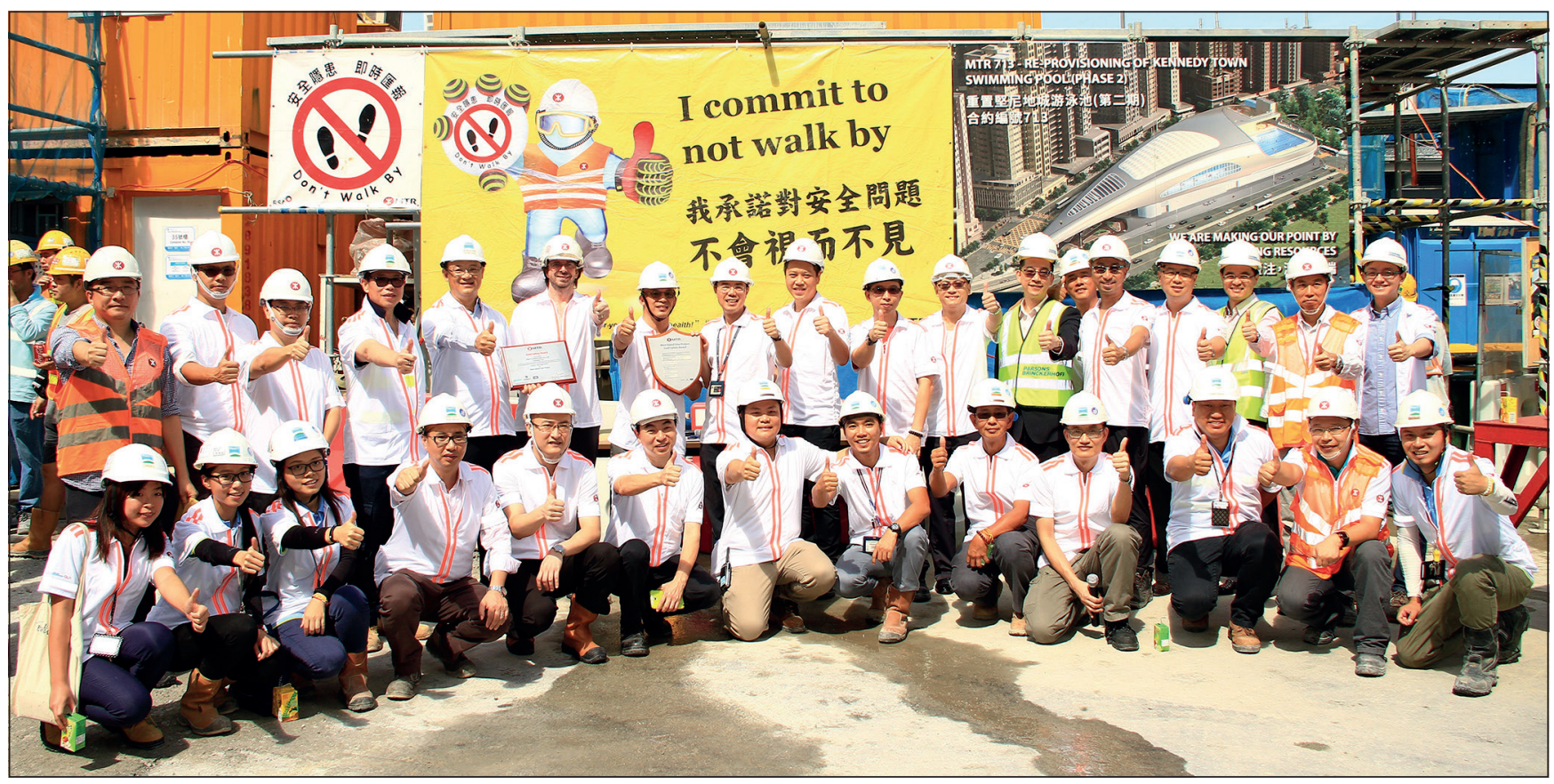

Figure 6. Team celebration after receiving the Gold Safety Award of the MTR West Island line 2015

In summary, the phase 2 contract has achieved the following key objectives

- project successfully tendered and constructed

- project completed early through use of an early-completion incentive

- no formal disputes and final account was agreed at completion

- following a learning curve, a strong project teamwork mentality was developed which contributed to successful delivery outcome

- the trial can be considered a success and consideration may be given to further application of NEC by the client.

\section{Awards received}

The phase 2 contract has won a number of awards in the areas of project management, contractor performance and care, construction management, quality, safety and hazards identification. The major awards include

a winner of NEC Large Project of the Year 2016

- highly commended for NEC Contractor of the Year 2017

- Gold Award of CIOB Construction Manager 2016

- Project of the Year Award 2017, winner of 2017 Construction/ Engineering Award and winner of 2017 Community Service/ Regional Development of Hong Kong Institute of Project Management

- Gold Safety Award of MTR Projects and MTR West Island Line 2015 (Figure 6)

- Considerate Contractors Site Merit Award (Non-public works) and Outstanding Environment Management \& Performance
Merit Award of 23rd Considerate Contractor Site Award Scheme 2017 of Development Bureau of HKSAR

- Considerate Contractors Site Merit Award (Non-public works) and Outstanding Environment Management \& Performance Merit Award of 22nd Considerate Contractor Site Award Scheme 2015 of Development Bureau of HKSAR

- 2017 Architecture and Design Trophy Awards of Perspective magazine, Hong Kong (Professional Architecture - Best Hotel, Resort or Leisure Destination category)

- 2017 ArcAsia Awards for Architecture of Architects Regional Council Asia (Gold)

- 2017 American Architecture Prize (Architectural Design/ Recreational Architecture category)

- 2017 nominated for an award (Community, Culture and Recreational projects) at the Cross-Strait Architectural Design Symposium and Awards of Hong Kong Institute of Architects.

Among these awards, the top award received was the NEC Large Project of the Year 2016. The phase 2 contract is the first and only project in Hong Kong that has received this top honour to date.

\section{Reference}

NEC (2013) NEC3 Engineering and Construction Contract. NEC, London, UK.

\section{How can you contribute?}

If you would like to comment on this paper, please email up to 200 words to the editor at journals@ice.org.uk.

If you would like to write a paper of 2000 to 3500 words about your own experience in this or any related area of civil engineering, the editor will be happy to provide any help or advice you need. 